\title{
Design Optimization of MEMS based LLC Tunable Resonant Converter for Power Supplies on Chip
}

\author{
Fahimullah Khan ${ }^{\text {a }}$, Yong Zhu, Member IEEE Junwei Lu, \\ Sr. Member IEEE,Dzung Dao \\ Queensland Micro \& Nanotechnology Centre \\ Griffith University, Nathan, Australia \\ afahimullah.khan@griffithuni.edu.au
}

Keywords: Tunable capacitor; Resonant converter; Magnetizing inductance; Leakage inductance; Metal MUMPs.

\begin{abstract}
In this paper, a novel MEMS based LLC converter is proposed for on chip power supplies. The design is optimized based on commercially available Metal MUMPs process for fabrication. The resonant frequency is optimized at $20 \mathrm{MHz}$ and MEMS based variable capacitor is fabricated on the chip to tune the peak resonance frequency of circuit which varies due to the load variations. The Design is simulated in FEM based numerical software COMSOL and Intellisuite. According to analysis the magnetizing inductance of $42 \mathrm{nH}$ and leakage inductance of $40 \mathrm{nH}$ has been achieved from $16 \mathrm{~mm}^{2}$ rectangular coil transformer. The total capacitance of $1500 \mathrm{pF}$ has been achieved from parallel plate capacitors and variation of $3 \mathrm{pF}$ has been achieved from variable capacitor.
\end{abstract}

\section{Introduction}

With the advancement in power converters many problems of pulse width modulation converters (PWM) have been solved by resonant converters. The high switching loss of the high frequency converters is the most difficult problem for the power supplies design engineers. The traditional resonant converter includes series resonant converter (SRC), parallel resonant converter (PRC) and series parallel resonant (SPRC) converters. The problem with series resonant converter is that light load switching frequency has to increase, to keep the output voltage regulated. In parallel resonant converter (PRC) circulating energy is much higher even at light load or no load conditions. In series parallel resonant converter (SPRC) the main problem arises with wide input range, which leads to high conduction and switching loss at high frequencies.

Multi-resonant LLC converter is an important counterpart of PWM and other resonant converters topologies. It can be used in wide range of applications such as mobile phones with switched mode power supplies increases battery life. Similarly it can be used in wireless power transfer for biomedical applications [1] and wireless sensor network for providing continuous power supply for wide range of application in sensor network [2].

Several designs of LLC have been presented in [3] and [4] and the performance and behavior are completely analyzed.The main drawback in these designs is that the miniaturized size of transformer could not be accomplished, which is the basic requirement of power supplies on chip. Similarly the load variation also shifts the peak resonance frequency of tank circuit. Thus, the input voltage frequency should vary with the variation of load to achieve regulated output.

On chip transformer has been presented in [5] for DC-DC converters having different dimensions, shapes, and core materials. In [6] racetrack shape has been employed for transformer coil with voltage gain of $-1 \mathrm{~dB}$ in $1-20 \mathrm{MHz}$ frequency range. The transformer has a turn ratio of $4: 4$ and a dimension of $2.1 \mathrm{~mm} \times 11.3 \mathrm{~mm}$. Integrated air core transformer is presented in [7]. The transformer is silicon-embedded coreless for DC-DC converter and optimized at $50 \mathrm{MHz}$ with the size of $2 \mathrm{~mm}^{2}$. Many power supplies on chip (PwrSoC) and power supplies in package (PwrSiP) have been presented in $[8,9]$ showing that PwrSiP have a higher power density than the conventional power modules. 
In this paper, a novel integrated LLC tank having tunable capacitor and transformer has been proposed for LLC resonant converters in power supplies on chip applications. The variable capacitor brings new dimension for LLC converter in which one has the freedom to tune the resonant frequency of resonant tank according to the load in order to maintain voltage regulation. The tuning capacitor is simulated in MEMS specialized software whereas the magnetic component transformer has been simulated in AC/DC module of COMSOL. The complete design is optimized in MEMS standard process, Metal MUMPs from MEMSCAP which is commercially available and low cost process.

\section{Proposed Design}

Resonant converter takes a square wave voltage signal from the half bridge MOSFETs topology. The energy in the resonant circuit circulates in the tank circuit and a part of it is delivered to the load through transformer as shown in fig. 1. The resonant circuit comprised of series capacitor $\mathrm{C}$, the series inductor $\mathrm{L}_{\mathrm{k}}$ and shunt inductor $\mathrm{L}_{\mathrm{m}}$ and the ideal transformer so that the energy can be transferred to the load. In proposed design these passive elements are integrated on the same chip with the extremely reduced size of transformer, making the converter a possible candidate for the applications of portable devices and wireless energy transmission for biomedical sensors.

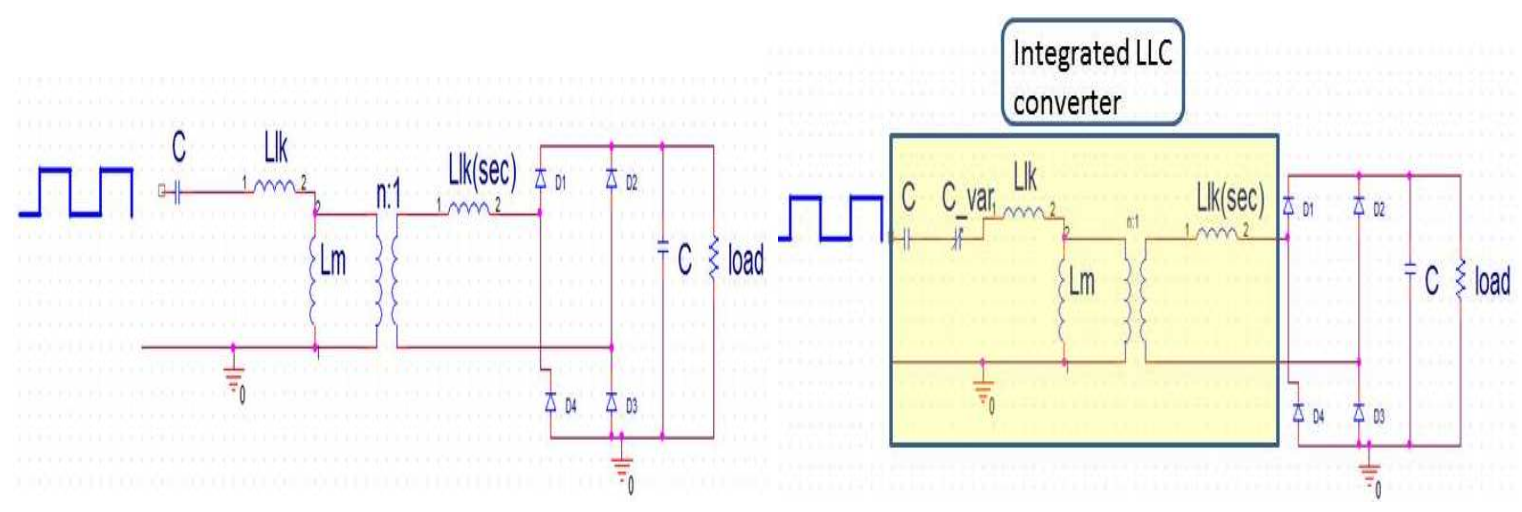

Fig 1(a). LLC resonant converter.(b) Integrated LLC resonant converter.

In the proposed design the resonant tank circuit is integrated on same substrate with the ability to tune the resonant frequency of the tank circuit as shown in fig.1(b). Thus it can overcome the problem of shifting of resonant frequency with the variation of load at the secondary side of transformer. The tank circuit parameters define the resonant frequency and as there are two magnetic elements so two resonant frequencies are present which are calculated by following equations.

$$
\begin{aligned}
& \mathrm{f}_{1}=1 / 2 \pi \sqrt{\mathrm{L}_{\mathrm{lk}} \mathrm{C}} \\
& \mathrm{f}_{2}=1 / \sqrt{2 \pi\left(\mathrm{L}_{\mathrm{m}}+\mathrm{L}_{\mathrm{lk}}\right) \mathrm{C}}
\end{aligned}
$$

The design guide lines are followed which are mentioned in [3] and parameters of resonant tank circuit are calculated from the above equations. The first resonance frequency which arises from the leakage inductance is about $20 \mathrm{MHz}$ and the second resonance frequency which arises due to the sum of leakage and magnetizing inductance is about $14.35 \mathrm{MHz}$.

Fig.2(a) shows the layout of LLC resonant converter. The transformer has $2 / 1$ turn ratio with $\mathrm{NiZn}$ ferromagnetic material glued at the top to achieve almost 1:1 ratio of leakage and magnetizing inductance, as illustrated in fig.2(b). Two fixed capacitors and one variable capacitor are fabricated on same chip to achieve total capacitance of $1500 \mathrm{pF}$. The purpose of two fixed capacitors instead of one is to avoid any imperfection in fabricating large thin film dielectric layer (Si3N4). The variation in the capacitance is about $3 \mathrm{pF}$ which can bring about $20 \mathrm{kHz}$ change in frequency. 


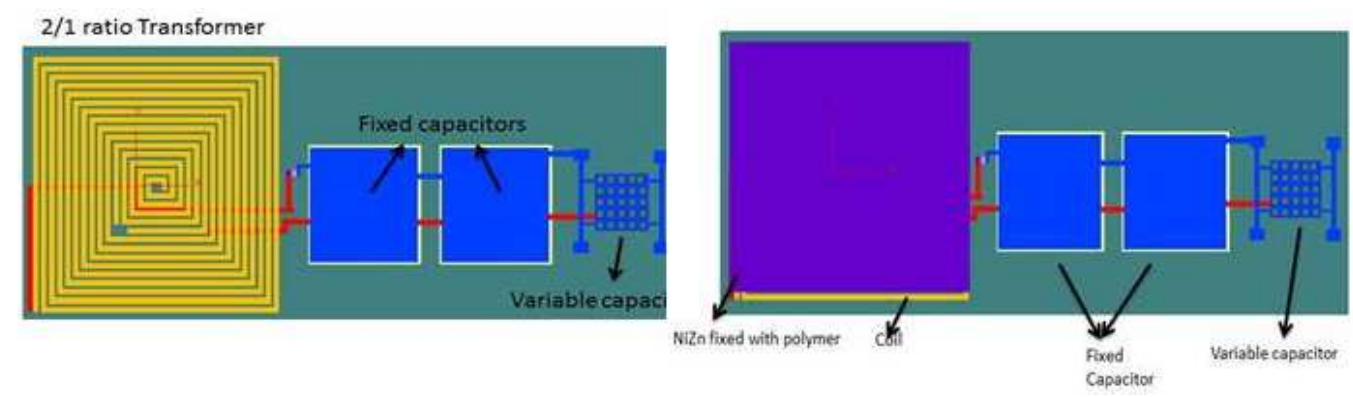

Fig 2.(a) Layout of LLC resonant converter in Blueprint (b)NiZn ferromagnetic material glued on top of transformer.

\section{Fabrication Process}

The design is optimized in commercially available low cost Metal MUMPs process and simulated in Virtual Clean Room module of Intellisuite. After simulation, 3D model has been built to validate the structure and fabrication accuracy. The step-by-step process is shown in fig.3.

The base wafer is $\mathrm{N}$-type silicon and a $2 \mu \mathrm{m}$ silicon dioxide is grown to provide electrical isolation from substrate. A $0.5 \mu \mathrm{m}$ PSG layer which acts as sacrificial layer is grown and patterned by photolithography process with the first mask layer as shown in fig. $3 \mathrm{~b}$ ). The third layer of nitride 1 with $0.35 \mu \mathrm{m}$ thickness is deposited and patterned with combination of nitride 2 layer. The nitride layers provide a protective encapsulation for the polysilicon as shown in fig3 (e). Fourth layer polysilicon film is $0.7 \mu \mathrm{m}$ thick, doped for resistor elements, and electrical cross-over routing, shown in fig.3(d). After poly nitride 2 is deposited, this is patterned with the same nitride1 mask layer. The sixth layer is oxide 2, which is $1.1 \mu \mathrm{m}$ of PSG and released at the final release step to free the mechanical layer. Anchor metal is the seventh deposition layer which provides anchors for the metal structure. A liftoff process provides thin layer of $\mathrm{Cr}$ and $\mathrm{Pt}$ only at the bottom of oxide2 anchors. The metal layer is $20 \mu \mathrm{m}$ of electroplated patterned nickel layer and $0.5 \mu \mathrm{m}$ gold layer is plated on top of nickel to provide pad for wire bonding as shown in fig.3 (g). The last layer is 1-3 $\mu \mathrm{m}$ thick gold layer which can be plated on sidewall of metal layer to provide low electrical contact resistance. In the proposed design transformer turns are obtained from the same layer. The final step is the release step in which all the sacrificial layers are removed and Si base is trenched.

Finally, powder NiZn ferromagnetic material is mixed with polymer and glued at the top of transformer to provide a transformer core only at the top.

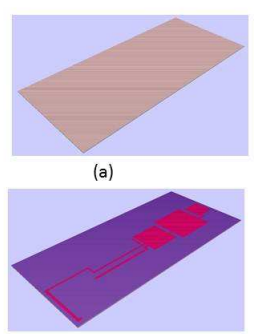

(d)

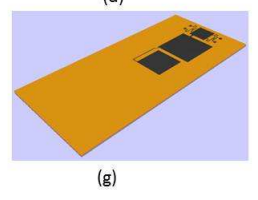

Fig. 3 Step by Step fabrication process

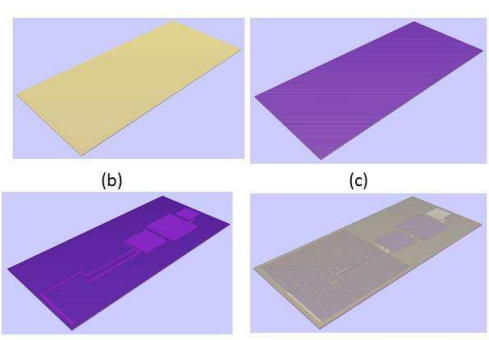

(e)
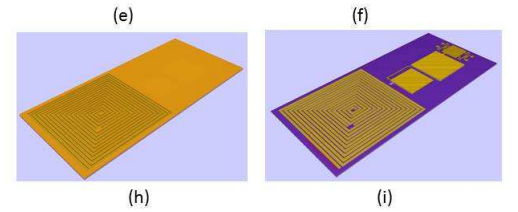


\section{Transformer design simulation}

The proposed transformer is simulated using 2D AC/DC module of COMSOL 4.3v. The magnetizing inductance and leakage inductance of transformer has been simulated using coil domain boundary condition provided in software and open and short circuiting of transformer secondary coil. Figs.4(a), and (b) respectively shows the magnetizing and leakage inductance between $1 \mathrm{MHz}$ and $30 \mathrm{MHz}$. The design is optimized at $20 \mathrm{MHz}$ and the simulation results shows mutual inductance of $42.5 \mathrm{nH}$ and leakage inductance of about $40.3 \mathrm{nH}$ are obtained from the $2 / 1$ ratio transformerwith a core on top.
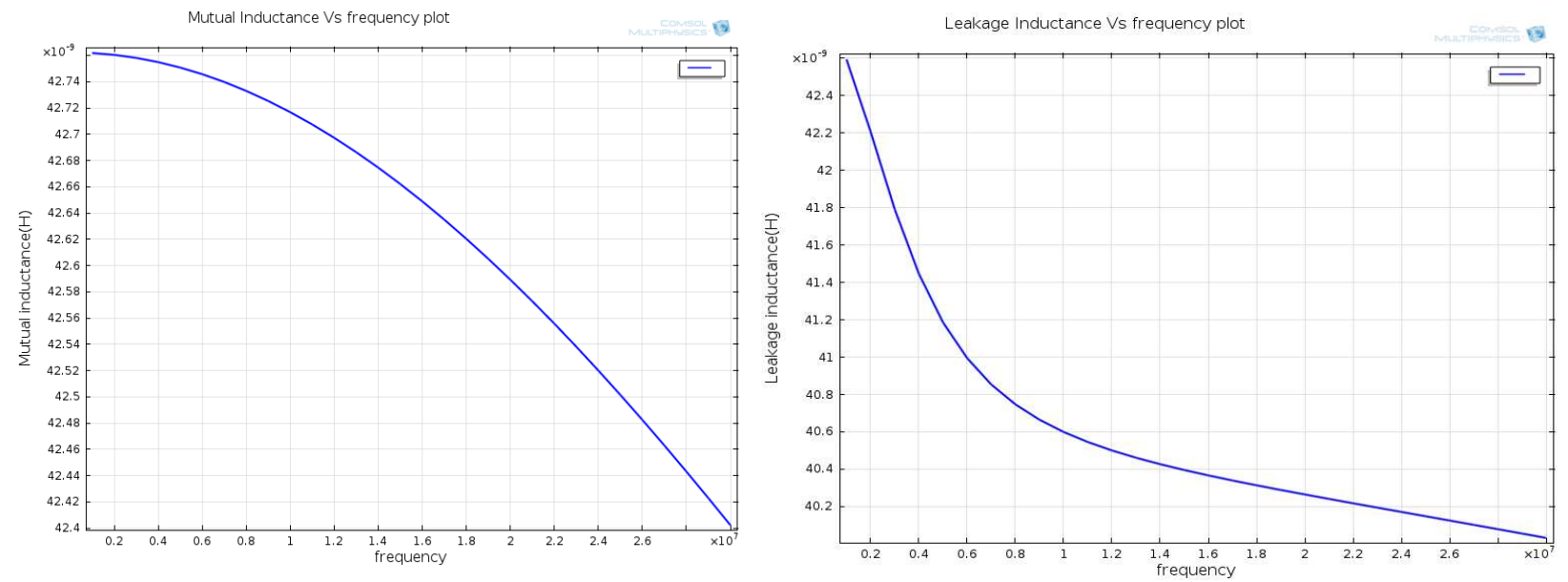

Fig.4(a)Mutual inductance vs frequenc plot. (b) Leakage inductance vs frequency plot.

\section{Variable Capacitor Simulation}

Fig. 6(a) shows the voltage versus displacement plot which shows that the curve is almost linear until $10.5 \mathrm{~V}$. After $10.5 \mathrm{~V}$ there is abrupt change in displacement due to pull-in voltage which is given by following equation. It is noted that pull in effect starts at $10.4 \mathrm{~V}$ and $0.72 \mu \mathrm{m}$ gap between two plates.

$$
\mathrm{V}_{\mathrm{p}}=\sqrt{8 \mathrm{kd}_{0}^{3} / 27 \epsilon \mathrm{A}}
$$

Where $\mathrm{k}$ is the spring constant of beams, do is the gap between the parallel plate capacitor, $\mathrm{\epsilon}$ is the permittivity of free space and ' $A$ ' is the area of parallel plate capacitor.

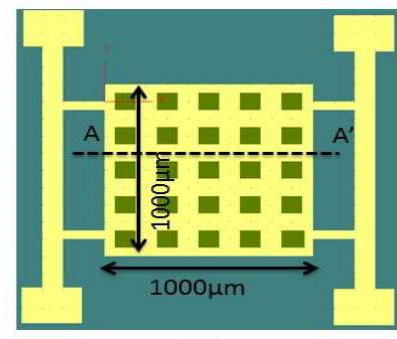

(a)

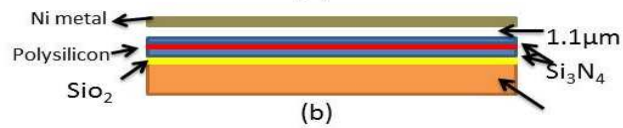

Fig.5(a) Layout of variable capacitor.(b).A-A' Cross sectional view of variable capacitor.

An H-type suspension variable capacitor is fabricated on the same substrate. The beam structure of variable capacitor is such that to restrict the motion of parallel plate in $\mathrm{x}$-axis and $\mathrm{y}$-axis and to allow only in z-axis displacement under the applied voltage. The gap between the Ni metal and the nitride layer is $1.1 \mu \mathrm{m}$ as shown in fig.5(b). The natural frequency of variable capacitor is $1.707 \mathrm{KHz}$ which is well below input signal( $20 \mathrm{MHz})$ to avoid resonance. 
Fig.6(b) shows that as voltage increases the gap between capacitor plates decreases as a results change in capacitance increases. Beyond $10.5 \mathrm{~V}$, there is sudden change in capacitance which is difficult to detect.
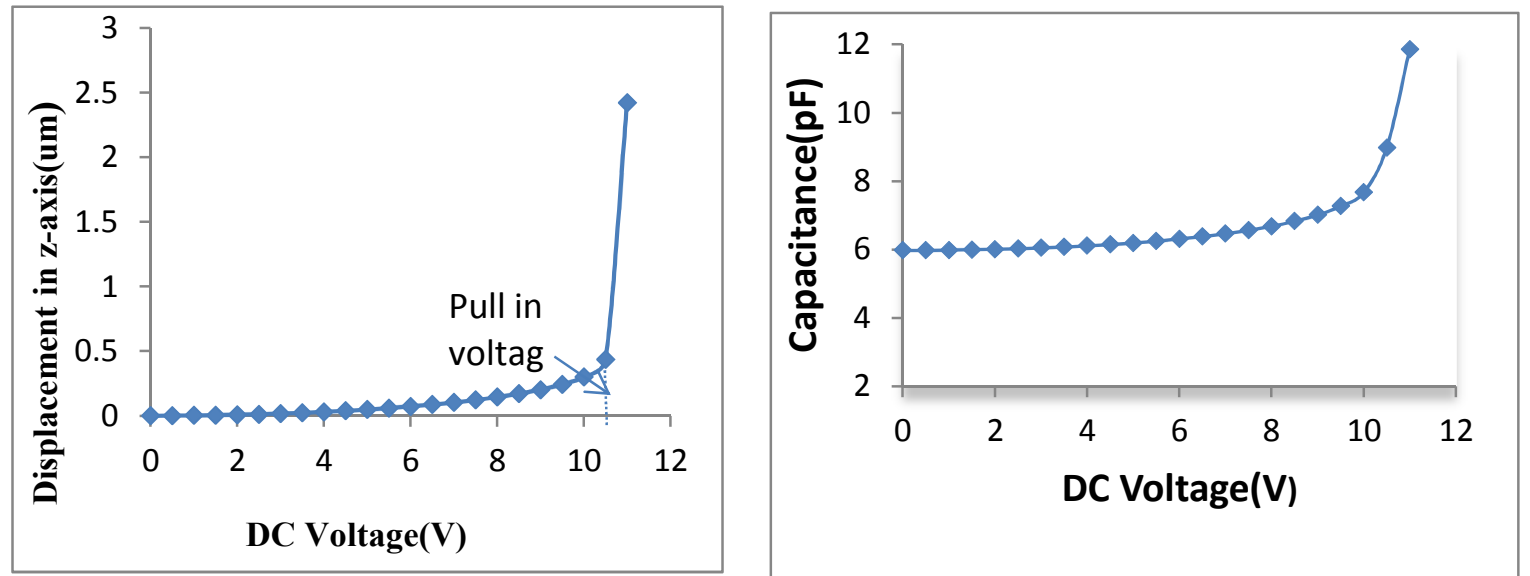

Fig. 6(a) Voltage vs displacement in z-axis plot.(b)Voltage vs change in capacitance plot.

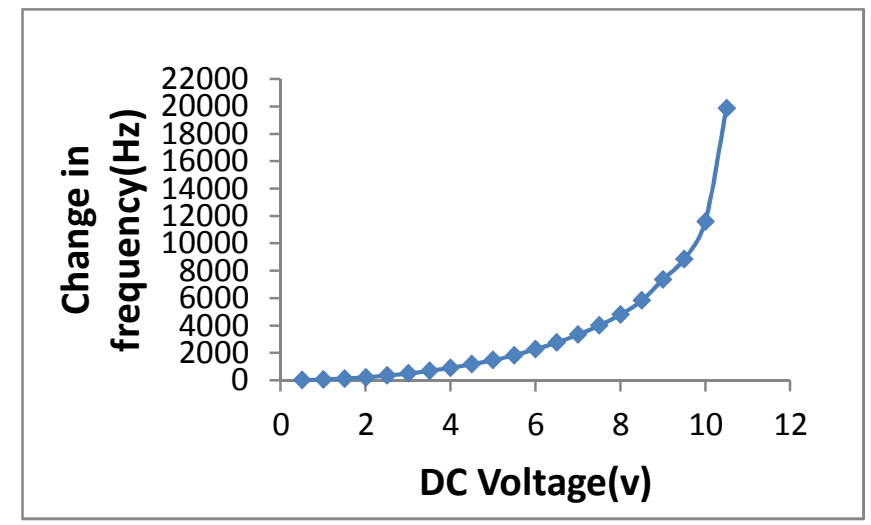

Fig.7 Voltage vs change in frequency plot.

Fig.7 shows that as voltage increases the change in frequency also increases from its original resonance frequency. It is noted that after $10.5 \mathrm{~V}$ there is sudden change in frequency, which is difficult to predict.

\section{Conclusions}

A new LLC resonant converter with resonance tuning has been proposed. The behavior of tuning capacitor has been simulated. The magnetic component is simulated in COMSOL and MEMS based variable capacitor is simulated in Intellisuite. The design is optimized in commercially available standard process MetalMUMPs which is a low cost reliable process. To improve magnetizing inductance NiZn ferromagnetic material is affixed at the top of transformer coil. It is observed that $42 \mathrm{nH}$ magnetizing inductance and $40 \mathrm{nH}$ leakage inductance have been obtained from $16 \mathrm{~mm}^{2}$ transformer size at frequency of about $20 \mathrm{MHz}$. The total capacitance of about $1500 \mathrm{pF}$ has been achieved from two capacitor connected in parallel. The total variation of about $3 \mathrm{pF}$ has been achieved from the variable capacitor at $10.5 \mathrm{~V}$. The low DC requirement of tuning variable make it suitable competitor for portable devices power supplies.

\section{Acknowledgment}

This work is supported by Griffith University Australia under "Griffith University New Researcher Grant" research fund. 


\section{References}

[1] T. S. Chan, C. L. Chen, LLC Resonant Converter for Wireless Energy Transmission system with PLL control, ICSET (2008). Taiwan, A247, pp. 136-139, (2008).

[2] Q. Fang, S Lee, Developing a wireless Implantable body sensor network in MICS band, IEEE Transactions on Information technology in biomedicine, vol. 15, no. 4, july 2011.

[3] S. De Simone, C. Adragna, C. Spini, Design guideline for magnetic integration in LLC resonant converters, International Symposium on power electronics, SPEEDAM, (2008), pp. 950-957.

[4] B. Lu, W. Liu, Y. Liang, F. C. Lee, Optimal Design Methodology for LLC resonant converter, IEEE, (2006), pp. 533-538.

[5] M. Mino, T. Yachi, A. Tago, K. Yanagisawa, and K. Sakakibara ,Planar Micro transformer with Monolithically-integrated rectifier diodes for Micro-switching converters, IEEE Transaction on Magnetics, Vol. 32, no. 2, March (1996), pp. 291-295.

[6] N. Wang, T. O’Donnell, S. Roy, S. Kulkarni, P. Mccloskey and C. O’ Mathuna , Thin Film Microtransformer integrated on Silicon for Signal Isolation, IEEE Transactions on Magnetics, vol. 43, no.6, June (2007), pp. 2719-2721.

[7] R. Wu, J. K. Sin, A novel Silicon-Embedded Coreless Transformer for Isolation DC-DC Converter Application. Proc. Of 23rd International Symposium on power Semiconductor Devices \& IC's, San Diego, May (2011), pp.352-355.

[8] S.C. Mathuna, T. Donnell, Magnetics on Silicon:An Enabling Technology for power supply on chip, IEEE Transaction on powerelectronics, vol. 20, no.3, May (2005), pp.585-592.

[9] K. Onizuka, H. Kawaguchi, M .Takamiya,Stacked-chip Implementation of on-chip buck converter for Power-Aware distributed power supply systems, IEEE, (2006). pp.127-130. 